\title{
Chromosome Karyotypes of Echinacea angustifolia var. angustifolia and E. purpurea
}

\author{
Luping Qu, Xiping Wang ${ }^{1}$, Eatherley Hood, Meihua Wang, and \\ Richard Scalzo \\ Gaia Herbs, Inc., 108 Island Ford Road, Brevard, NC 28712
}

Additional index words. medicinal plants, chromosome variation

Abstract. Chromosome karyotypes of the most commonly cultivated and medicinally used Echinacea taxa, E. angustifolia DC. var. angustifolia and E. purpurea (L.) Moench., were analyzed. The chromosomes of both taxa are medium in length, ranging from 4.12 to 5.83 $\mu \mathrm{m}$ in $E$. angustifolia var. angustifolia and 3.99 to $6.08 \mu \mathrm{m}$ in E. purpurea. No abrupt length changes in the chromosomes were noted. The karyotypes of the two species are generally similar, but a distinguishable feature exists in one pair of chromosomes. The centromere of chromosome pair 10 is subterminally located in $E$. purpurea, but terminally located in E. angustifolia var. angustifolia, which can be readily recognized in mitotic metaphase cell plates. This finding may provide useful information for Echinacea evolutionary, genetic, and breeding studies.

Chromosome size and morphology may help indicate evolutionary relationships among plant species (Clark and Wall, 1996). In plant taxonomy, breeding, and genetic studies, information about chromosome karyotypes can be useful in species identification and analysis of hybrid populations. Native to North America, Echinacea species have an important place in herbal medicine. Echinacea has long been used by Native Americans to treat many conditions, including venomous bites, rabies, cold, headache, and stomach cramps (Foster, 1991; Kindscher, 1989; Li, 1998). Its nonselective, immune-enhancing properties have promoted the use of and demand for Echinacea products in recent years and, consequently, its field production. Cultivation of Echinacea has gained international attention and has been conducted in many countries, including the United States, Canada, Germany, Norway, Romania, Finland, Australia, Poland, Russia, New Zealand, Egypt, and China (Dou et al., 2001; El-Gengaihi et al., 1998; Finger et al., $1998 ; \mathrm{Li}, 1998)$. Of the nine species and two varieties in Echinacea recognized by McGregor (1968), E. angustifolia var. angustifolia and E. purpurea are used most commonly (Li, 1998), followed by E. pallida.

Chromosome numbers and ploidy levels have been investigated in Echinacea. Echinacea angustifolia var. angustifolia and $E$. purpurea are diploids with a somatic chromosome number of $2 \mathrm{n}=22$. Echinacea pallida is a tetraploid $(2 n=44)$ and was suspected to

Received for publication 20 Dec. 2002. Accepted for publication 9 May 2003. This publication is made possible by grant number 1R44AT771-01 from the National Center for Complementary and Alternative Medicine. The seed materials supplied by NCRPIS, USDA, and Dr. J. Hinshaw's assistance in microscopy are greatly acknowledged.

${ }^{1}$ To whom reprint requests should be addressed. E-mail address: x0w@gaiaherbs.com be derived from chromosome doubling of a hybrid between $E$. simulata $\mathrm{McGregor}$ and $E$. sanguinea Nutt. (McGregor, 1968). Chromosome karyotypes of Echinacea species have been reported to be quite similar (McGregor, 1968); however, precise descriptions and visual presentation of karyotypes of these species have not been published. This research was to analyze the karyotypes of E. angustifolia var. angustifolia and E. purpurea.

\section{Materials and Methods}

Root tips from germinating seeds and young leaves from field-grown plants were used for chromosome preparation. Echinacea angustifolia var. angustifolia and E. purpurea seeds were provided by the North Central Regional Plant Introduction Station (NCRPIS), U.S. Dept. of Agriculture (USDA) (Ames, Iowa), and purchased from Johnny's Selected Seeds (Albion, Maine), Wind River Seed (Manderson, Wyo.), and Richters (Goodwood, Ont., Canada) (Table 1). Seed germination was conducted in a growth chamber held at $25^{\circ} \mathrm{C}$. Seeds were soaked with deionized (DI) water in beakers for 15 min before they were placed in petri dishes on two layers of Whatman no. 1 filter paper thoroughly wetted with DI water. Germinating seeds with 1 - to 5 -mm radicles were treated with $0.08 \%$ colchicine solution for $\approx 3.5 \mathrm{~h}$ in small vials at room temperature. After colchicine treatment, the seeds were placed in freshly prepared Carnoy's fixative II (1 glacial acetic acid : 3 chloroform : 6 ethanol) (Li and Zhang, 1991) and stored in a refrigerator for at least $24 \mathrm{~h}$ before use.

The remaining seeds were also sown in a greenhouse in cell flats in mid-March (the USDA seeds were germinated in the growth chamber and transplanted into cell flats in late April after germination), and plants were transplanted into a field at Gaia Herbs Farm (Brevard, N.C.) in mid- to late May. Vegetative buds that were elongating were excised from the field-grown plants at $\approx 11: 00$ AM in early Sept. 2002 and immediately treated as in root tip preparation. Some of the E. angustifolia var. angustifolia plants and most of the $E$. purpurea plants were blooming at the time of sampling.

Plant morphologies of E. angustifolia var. angustifolia and E. purpurea are readily distinguishable. Only one E. angustifolia var. angustifolia was noted in $\approx 4000$ plants grown from the commercial E. purpurea seed lots and vice versa, and no off-types were found in the USDA seeds. The morphological characteristics of the field-grown plants matched well with the published species descriptions (McGregor, 1968). Identities were also confirmed by plant taxonomist William Hess (Morton Arboretum, Lisle, Ill.). We have labeled the field-grown plants sampled for chromosome preparations, and voucher specimens from these plants will be made and deposited at Gaia Herbs, Inc.

For chromosome preparation, the fixed samples were placed in DI water for $\approx 30 \mathrm{~min}$ at room temperature, and then root tips of $\approx 1 \mathrm{~mm}$ or young leaf tips were excised and hydrolyzed in $1 \mathrm{~N} \mathrm{HCl}$ for $\approx 6.5 \mathrm{~min}$ at $60^{\circ} \mathrm{C}$. The tips were then transferred to DI water and held for $\approx 30$ $\mathrm{min}$ at room temperature. Chromosome slides were prepared by macerating the tips on slides in carbol fuchsin stain ( $\mathrm{Li}$ and Zhang, 1991) and squashing under cover glass. Chromosome examination and photography were conducted by using a microscope (Zeiss IM35) under $1000 \times$ magnification.

For each seed source, chromosome evaluation was conducted from at least five root tips (five seeds) and young leaves from two plants. Chromosome measurements were made on the enlarged prints and converted to micrometers by relating measurements made in the microscope with a micrometer. Karyotype analysis was based on at least seven high-quality metaphase cell plates.

Table 1. Seed sources and origins of E. angustifolia var. angustifolia and E. purpurea used in chromosome evaluation.

\begin{tabular}{llll}
\hline Species & Accession no. & Seed origin & \multicolumn{1}{c}{ Provider } \\
\hline E. angustifolia & Ames 23930 & Iowa & NCRPIS , USDA \\
E. angustifolia & Ames24060 & Kansas & NCRPIS, USDA \\
E. angustifolia & 13370 & Wyoming & Wind River Seed \\
E. angustifolia & 16420 & Minnesota & Johnny's Selected Seeds \\
E. purpurea & Ames23967 & North Carolina & NCRPIS, USDA \\
E. purpurea & Ames25104 & Louisiana & NCRPIS, USDA \\
E. purpurea & S2280 & Oregon & Richters \\
E. purpurea & 12448 & Colorado & Wind River Seed \\
\hline
\end{tabular}

${ }^{\mathrm{z} N o r t h}$ Central Regional Plant Introduction Station. 

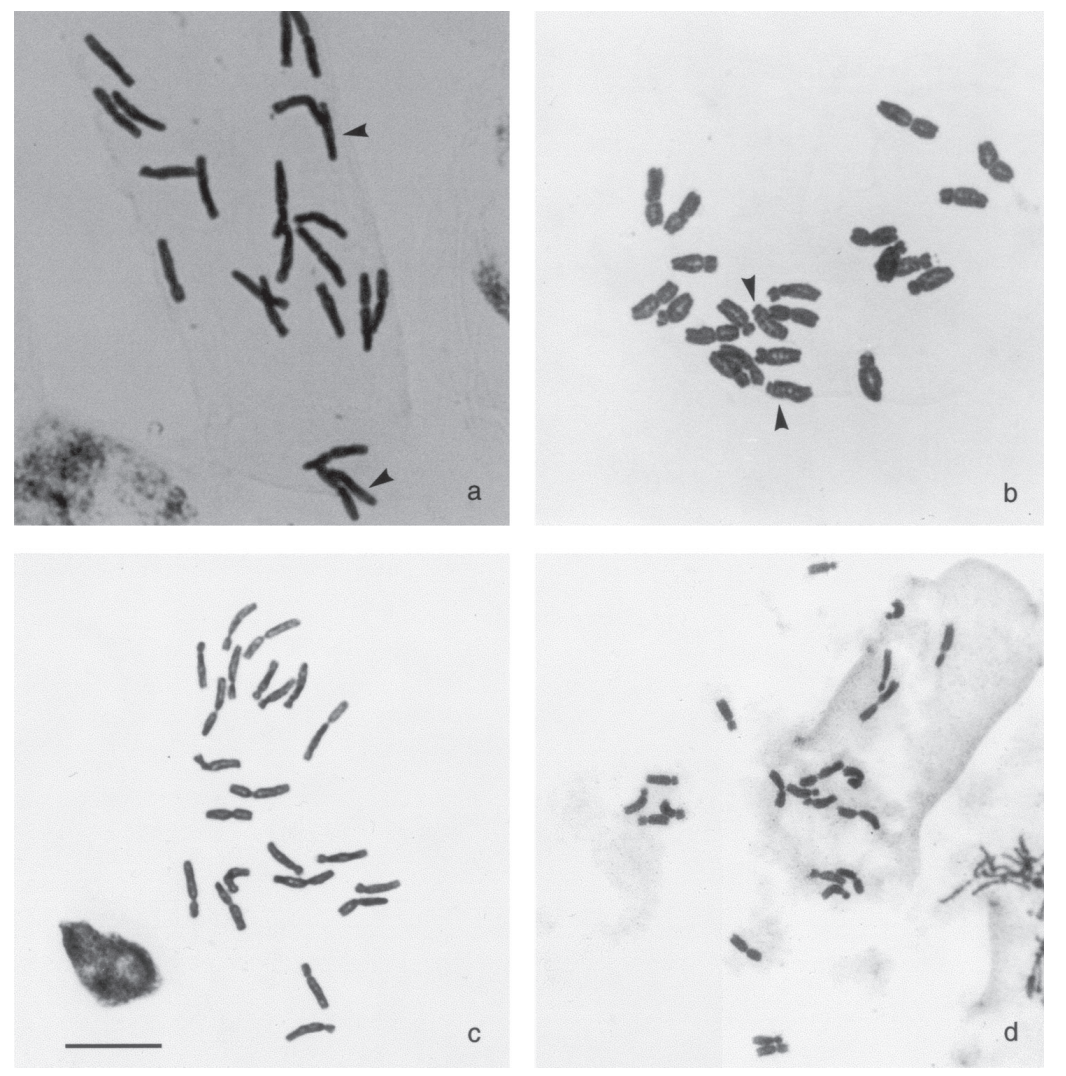

Fig. 1. Echinacea metaphase chromosomes prepared from root tips of germinating seeds: (a) early metaphase stage and (b) metaphase stage of E. angustifolia var. angustifolia; and (c) early metaphase stage and (d) metaphase stage of E. purpurea. Arrows indicate the chromosomes with a terminal centromere region. $\mathrm{Bar}=10 \mu \mathrm{M}$.

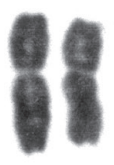

I

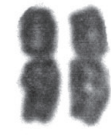

II

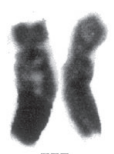

III

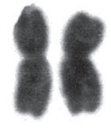

IV

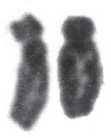

V

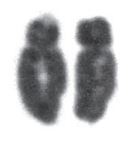

VI

a

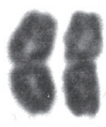

VII

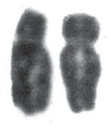

VIII

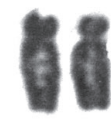

IX

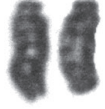

X

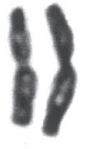

IV

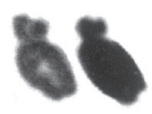

XI

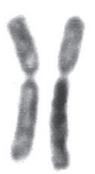

I

b

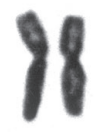

VII

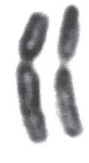

II

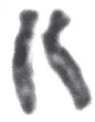

VIII

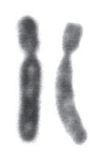

III

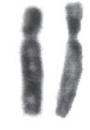

V

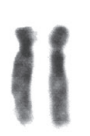

X

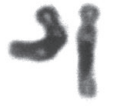

XI

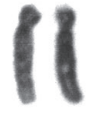

IX

\section{Results and Discussion}

Typical mitotic metaphase cell plates are shown in Figure 1. As previously reported (McGregor, 1968), chromosome numbers of E. angustifolia var. angustifolia and E. purpurea are $2 \mathrm{n}=22$. Results of the karyotype analysis are presented in Figure 2 and Table 2. In general, the chromosomes of both species are medium in length, ranging from 4.12 to $5.83 \mu \mathrm{m}$ in E. angustifolia var. angustifolia and from 3.99 to $6.08 \mu \mathrm{m}$ in E. purpurea. No abrupt length changes in the chromosomes were noted. Both species have four pairs of chromosomes with median-region centromeres and two pairs with submedian-region centromeres. The remaining five pairs have subterminal-region centromeres in E. purpurea. In E. angustifolia var. angustifolia, four of the five remaining pairs have subterminal-region centromeres, but chromosome pair 10 has its centromeres in the terminal region. Pair 10 can be readily recognized in E. angustifolia when compared with those of E. purpurea. The other pairs of chromosomes of the two species cannot be readily distinguished without detailed measurements. Within-species karyotypic variation was not observed in this study.

The readily distinguishable chromosome pair 10 in E. angustifolia might be used in hybrid identification in crosses of these two species. Although some quantitative differences in chromosome length and arm ratios exist in other pairs of the variety and the species, the overall similarity of the chromosomes and their subtle differences may make them unsuitable in species identification. Further research using chromosome banding (Tuna et al., 2001) or fluorescent dye staining (Schwarzacher et al., 1992) may help discriminate these pairs in more detail.

The plant materials used in this research represent four different growth locations (four states in the United States) for both taxa (Table 1), and no within-species karyotypic variation was observed. This may indicate that karyotypic differentiation, which is particularly prominent due to the presence of the pair of terminal-region centromere chromosomes in E. angustifolia var. angustifolia, is broadly true in the two taxa. It may be interesting to examine whether chromosome karyotype differences exist among other species in Echinacea.

\section{Literature Cited}

Clark, M.S. and W.J. Wall. 1996. Chromosomes, the complex code. Chapman and Hall, London. p. 237-243.

Dou, D., S. Cui, Y. Cao, Y. Yan, and F. Shuai. 2001. Assaying of cichoric acid in introduced plant of Echinacea purpurea. Zhong Cao Yao 32:987-988.

El-Gengaihi, S.E., A.S. Shalaby, E.A. Agina, and S.F. Hendawy. 1998. Alkylamides of Echinacea purpurea as influenced by plant ontogeny and fertilization. J. Herbs Spices Medicinal Plants 5:35-41.

Finger, P., A. Bertram, and A.U. Bomme. 1998. Selective thermal weed control on medicinal and

Fig. 2. Chromosome karyogram of: (a) E. angustifolia var. angustifolia prepared from Fig. 1b; and (b) E. purpurea prepared from Fig. 1c. Bar $=10 \mu \mathrm{M}$. 
Breeding, Cultivars, Rootstocks, \& Germplasm Resources

Table 2. The chromosome (Chr.) karyotypes of E. angustifolia var. angustifolia (E.a) and E. purpurea (E.p). ${ }^{2}$

\begin{tabular}{|c|c|c|c|c|c|c|c|c|c|c|}
\hline \multirow[b]{2}{*}{ Chr. } & \multicolumn{2}{|c|}{ Total length } & \multicolumn{2}{|c|}{ Long arm } & \multicolumn{2}{|c|}{ Short arm } & \multicolumn{2}{|c|}{ Arm ratio } & \multicolumn{2}{|c|}{ Chr. type ${ }^{x}$} \\
\hline & E.a & E.p & E.a & E.p & E.a & E.p & E.a & E.p & E.a & E.p \\
\hline $\bar{I}$ & $5.83 \pm 1.03$ & $6.08 \pm 1.02$ & $3.36 \pm 0.61$ & $3.53 \pm 0.59$ & $2.47 \pm 0.43$ & $2.55 \pm 0.42$ & $1.36 \pm 0.06$ & $1.38 \pm 0.07$ & $\mathrm{~m}$ & $\mathrm{~m}$ \\
\hline II & $5.61 \pm 0.98$ & $5.61 \pm 1.08$ & $3.14 \pm 0.56$ & $3.27 \pm 0.64$ & $2.47 \pm 0.42$ & $2.33 \pm 0.43$ & $1.27 \pm 0.05$ & $1.40 \pm 0.07$ & $\mathrm{~m}$ & $\mathrm{~m}$ \\
\hline III & $4.93 \pm 1.01$ & $5.16 \pm 0.96$ & $3.81 \pm 0.79$ & $3.59 \pm 0.69$ & $1.12 \pm 0.21$ & $1.57 \pm 0.29$ & $3.40 \pm 0.13$ & $2.29 \pm 0.09$ & st & $\mathrm{sm}$ \\
\hline IV & $4.93 \pm 0.89$ & $5.15 \pm 0.84$ & $2.73 \pm 0.69$ & $2.80 \pm 0.48$ & $2.20 \pm 0.21$ & $2.35 \pm 0.39$ & $1.24 \pm 0.08$ & $1.19 \pm 0.05$ & $\mathrm{~m}$ & $\mathrm{~m}$ \\
\hline V & $4.89 \pm 0.76$ & $4.75 \pm 0.91$ & $3.62 \pm 0.55$ & $3.27 \pm 0.61$ & $1.27 \pm 0.18$ & $1.48 \pm 0.28$ & $2.85 \pm 0.07$ & $2.21 \pm 0.06$ & $\mathrm{sm}$ & $\mathrm{sm}$ \\
\hline VI & $4.84 \pm 0.73$ & $4.57 \pm 0.82$ & $3.45 \pm 0.53$ & $3.79 \pm 0.69$ & $1.39 \pm 0.21$ & $0.78 \pm 0.14$ & $2.48 \pm 0.10$ & $4.86 \pm 0.08$ & $\mathrm{sm}$ & st \\
\hline VII & $4.82 \pm 0.85$ & $4.50 \pm 0.89$ & $2.53 \pm 0.44$ & $2.67 \pm 0.54$ & $2.29 \pm 0.42$ & $1.83 \pm 0.34$ & $1.10 \pm 0.05$ & $1.46 \pm 0.10$ & $\mathrm{~m}$ & $\mathrm{~m}$ \\
\hline VIII & $4.53 \pm 0.92$ & $4.48 \pm 0.76$ & $3.81 \pm 0.77$ & $3.81 \pm 0.63$ & $0.72 \pm 0.14$ & $0.67 \pm 0.12$ & $5.31 \pm 0.07$ & $5.69 \pm 0.06$ & st & st \\
\hline IX & $4.31 \pm 0.83$ & $4.22 \pm 1.02$ & $3.32 \pm 0.65$ & $3.21 \pm 0.74$ & $0.99 \pm 0.18$ & $1.01 \pm 0.27$ & $3.36 \pm 0.04$ & $3.18 \pm 0.05$ & st & st \\
\hline X & $4.30 \pm 0.79$ & $4.12 \pm 0.73$ & $3.99 \pm 0.74$ & $3.25 \pm 0.59$ & $0.31 \pm 0.06$ & $0.87 \pm 0.14$ & $12.87 \pm 0.12$ & $3.73 \pm 0.13$ & $\mathrm{t}$ & st \\
\hline XI & $4.12 \pm 0.81$ & $3.99 \pm 0.99$ & $3.36 \pm 0.67$ & $3.00 \pm 0.73$ & $0.76 \pm 0.16$ & $0.99 \pm 0.26$ & $4.42 \pm 0.08$ & $3.03 \pm 0.09$ & st & st \\
\hline
\end{tabular}

${ }^{2}$ Chromosome type nomenclature is based on Levan et al. (1964), and chromosome length is in $\mathrm{mm}$.

${ }^{y}$ Arm ratio = length of the long arm : length of the short arm.

${ }^{\mathrm{x}} \mathrm{m}=$ median region centromere; $\mathrm{sm}=$ submedian region centromere; $\mathrm{st}=$ subterminal region centromere; and $\mathrm{t}=$ terminal region centromere.

spice plants. Zeischrift für Arznei- \& Gewürzpflanzen 3(2):70-76.

Foster, S. 1991. Echinacea: Nature's immune enhancer. Healing Arts Press. Rochester, Vt.

Kindscher, K. 1989. Ethnobotany of purple coneflower (Echinacea angustifolia, Asteraceae) and other Echinacea species. Econ. Bot. 43:498-507.

Li, M. and M. Zhang. 1991. Technology for plant chromosome research. Northwest Forest Univ.
Press, Shenyiang, China. p. 31-39.

Li, T.S.C. 1998. Echinacea: Cultivation and medicinal value. HortTechnology 8:122-129.

Levan, A., K. Fregda, and A.A. Sandberg. 1964. Nomenclature for centromeric position on chromosomes. Hereditas 52:201-220.

McGregor, R.L. 1968. The taxonomy of the genus Echinacea (Compositae). Univ. of Kansas Sci. Bul. 48:113-142.

Tuna, M., K.S. Gill, and K.P. Vogel. 2001. Karyotype and C-banding patterns of mitotic chromosomes in diploid bromegrass (Bromus riparius Rehm). Crop Sci. 41:831-834.

Schwarzacher, T., K. Anamthawat-Jonsson, G.E. Harrison, A.K.M.R. Islam, J.Z. Jia, I.P. King, A.R. Leitch, T.E. Miller, S.M. Reader, W.J. Rogers, M. Shi, and J.S. Heslon-Harrison. 1992. Genomic in situ hybridization to identify alien chromosomes and chromosome segments in wheat. Theor. Appl. Genet. 84:778-786. 